\title{
Numerical investigation of heat transfer and fluid flow characteristics inside a wavy channel
}

Gong-Nan Xie · Qiu-Wang Wang $\cdot$ Min Zeng · Lai-Qin Luo

Published online: 2 February 2007

(C) Springer-Verlag 2007

Erratum to: Heat Mass Transfer

DOI 10.1007/s00231-006-0133-7

Due to a processing error, the presentation of Eq. 18 was incorrect. The correct version is given below.

SMAX/flowin $<5 \times 10^{-6}$,

The online version of the original article can be found at http://dx.doi.org/10.1007/s00231-006-0133-7.

G.-N. Xie · Q.-W. Wang ( $₫)$ · M. Zeng · L.-Q. Luo State Key Laboratory of Multiphase Flow in Power Engineering, Xi'an Jiaotong University,

Xi'an, Shaanxi 710049, China

e-mail: wangqw@mail.xjtu.edu.cn 